\title{
THE INDEFENSIBLE SELF-DEFENSE ARGUMENT
}

\author{
Howard Hewitt
}

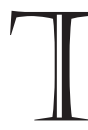

7 HE SELF-DEFENSE ARGUMENT is an argument for a woman's right to abortion on the grounds that it is an exercise of her right to defend her bodily the case that he occupies his mother's body in a particularly intimate way and, in an unwanted pregnancy, without her ongoing consent. These facts require us to concede that abortion is an exercise of a woman's right to defend herself from those who would use her body without her consent, regardless of the moral status of the fetus or any of the other facets of the relationship between a woman and her unwanted fetus. If sound, this argument would show that abortion is morally permissible in any case of unwanted pregnancy prior to the viability of the fetus. The self-defense argument is a robust, uncompromising defense of abortion rights, and while I will argue it fails to establish its conclusion, its failure has something to teach us about the abortion controversy.

I will argue for three claims in what follows: First, that the self-defense argument is unsound. Second, that a crucial assumption motivating the self-defense argument-namely, that we are to understand the mother-fetus relationship as a relationship governed by the same norms that govern intimate bodily relationships between normal adult human beings — not only fails to support a woman's right to abortion but also leads to the opposite conclusion. A commitment to understanding the mother-fetus relationship in this way leads to the conclusion that abortion in typical cases of unwanted pregnancy is morally impermissible, at least on the assumption that the fetus is a person. This leaves us with a choice: accept the moral impermissibility of abortion or reject the commitment. I argue that we all, abortion defender and critic alike, have good reason to reject the commitment, the third claim I aim to establish.

The paper goes like so: In section 1, I explain the self-defense argument and how its premises must be interpreted in order for it to be plausible. In section 2, I provide a counterexample to one of the self-defense argument's premises. The premise is that in any case where another person is using one's body in an intimate way without one's consent, one may use lethal force to stop that use, given 
that no other means are available. I show that this is false and that the premise cannot be successfully revised, thereby establishing that the self-defense argument is unsound.

In section 3, I mount an analogy argument from my counterexample to the conclusion that abortion is morally impermissible in typical cases of unwanted pregnancy. I show that what drives us to that conclusion is the self-defense argument's particular commitment to applying the norms governing intimate bodily contact between normal adults to the mother-fetus relationship. This commitment leads to the conclusion that abortion in typical cases of unwanted pregnancy is morally impermissible. I also show that this commitment implies that cases of voluntary conception constitute impermissible violations of a fetus's right to bodily autonomy, and so even though the commitment has implications amenable to the abortion critic, it is not something he can accept.

Section 4 concludes, in light of the foregoing, that we should reject that commitment and the self-defense argument along with it.

\section{THE SELF-DEFENSE ARGUMENT}

We are committed to a limited right of self-defense against persons using our bodies without our consent, including lethal self-defense in cases where the use is especially serious and there are no nonlethal means available to avoid it. The self-defense argument holds that abortion is an exercise of this right by a mother against her unwanted fetus. Abortion, then, is morally permissible, self-defensive killing, or can be justified as such for any unwanted pregnancy prior to the viability of the fetus. And this will be the case even if we assume that the fetus is a person from conception on.

The argument goes like so.

1. Any unwanted pregnancy is a serious, nonconsensual use of one person's body by another.

2. Any serious, nonconsensual use of one person's body by another justifies lethal self-defense.

3. So, any unwanted pregnancy justifies lethal self-defense.

I state the argument in this way to note a symmetry that will become important later on. Needless to say, for those who use this argument as a defense of abortion, the "user" is the fetus, and it is the mother who is thereby licensed to use lethal force against him. (Keep in mind that lethal self-defense will only be justified if there are no nonlethal means available, which, in this context, means 
that the conclusion will only justify abortion that kills the fetus up to the point of viability, after which the use relation can be ended nonlethally.)

All the defenders of this argument I am aware of motivate it by making an analogy between unwanted pregnancy and rape. ${ }^{1}$ A woman may, if no other means are available, kill a man if he uses or threatens to use her body sexually without her consent. A rapist is liable to killing, even if the woman begins a sexual encounter with a man and then changes her mind; if he does not stop, she may use lethal force to stop him, given that no lesser means could. The purveyors of the self-defense argument argue that the relationship between a pregnant woman and her unwanted fetus is, while not in every particular the same, morally comparable to the relationship between a victim and her rapist, and so the mother may permissibly use lethal force to end her unwanted pregnancy. (Note: I warn the reader that in what's coming there are descriptions of sexual assault, and, while I have tried to make the discussion as palatable as I can, the subject is impossible to avoid, given the rape analogy and the purpose it serves in underwriting the self-defense argument.)

Before moving on to assess the self-defense argument, I want to linger a bit on the analogy between sexual assault and unwanted pregnancy. The norms that govern sexual relations between normal adult human beings are not ambiguous. And they imply that no person has a right to use another person's body sexually. For another person to permissibly use your body in such a way requires your ongoing consent. And if a permissible use of your body by another requires your ongoing consent, that person does not, indeed cannot, have a right to so use your body. We can see this in the fact that a woman cannot be responsible for a sexual assault in any sense that would give her assailant a right to carry out the assault. There can be no such right. If partisans of the self-defense argument are right about the nature of the relationship between mother and fetus, then the fetus cannot have a right to use his mother's body, no matter what her role in bringing about the pregnancy, or what other relation she might have to the fetus. Much of the appeal of the self-defense argument is that it would dispense with the need to worry about considerations an abortion critic might adduce for the claim that the fetus has acquired a right to use his mother's body. If the rape analogy is apt, there can be no such right.

A great deal, then, rides on the analogy, and while there seem to be a number

1 See Little, "Abortion, Intimacy, and the Duty to Gestate"; Long, "Abortion, Abandonment, and Positive Rights"; McDonagh, Breaking the Abortion Deadlock; and Regan, "Rewriting Roe v. Wade." These writers make the same argument using the same analogy, but there is a difference in the rhetoric with which the analogy is pursued, with Little and Regan measured, and Long and McDonagh red in tooth and claw. 
of differences between sexual assault and unwanted pregnancy, partisans of the self-defense argument believe that the differences do not, when properly considered, make a difference. We will take a look at them now.

One might think the threat the rapist poses to an innocent person and the threat the unwanted fetus poses to his mother differ in their seriousness because they involve different amounts (or kinds) of harm, and so one might deny that the particular threat the fetus poses would justify lethal self-defense, whereas the threat a rapist poses does. That is, we could view a forced pregnancy as less harmful to a woman than a rape and so question whether the use relationship involved in premise 1 is of the same seriousness involved in premise 2. But even if we grant that there are different amounts of harm involved, this will not affect the validity of the self-defense argument. If someone threatened to stick something, or someone, in your body against your will in the way a fetus is in his mother's body, then it would be morally permissible to use force to stop himlethal force if necessary-even if the threatened violation, somehow, was not as traumatic as being raped. If there is a problem with the self-defense argument, it is not because the seriousness of the harm involved in a forced carriage does not rise to a level that might justify lethal self-defense. So, we should concede that the relation between mother and fetus is serious enough to do the work the argument needs it to do.

A more important issue is what we are to make of the claim that the fetus is using his mother's body. Unlike a rapist, the fetus is innocent of any wrongdoing, and the argument seems to require us to think of the fetus as an invader of his mother's body, a violator of her bodily integrity, which she may, if she wishes, use lethal means to expel. That the fetus's interests are served by remaining in his mother's body does not make him a user of her body in the sense that he intends to treat her as an instrument to secure his ends, and if this is the sort of use that must be involved for lethal self-defense to be justified, the argument equivocates. We cannot interpret "nonconsensual use" as involving agency on the part of the user without making the first premise false. And it would appear that this is just the sort of use that, as the rape analogy suggests, paradigmatically justifies lethal self-defense.

This being so, we need a sense of "nonconsensual use" that does not involve an exercise of agency on the part of the "user," but will justify lethal self-defense in any case where the relation obtains. And this will be tricky. If "nonconsensual use" of the mother's body by the fetus means that the fetus is in her body and she wants him out, then the first premise will be true, at least for any woman that seeks to end her pregnancy by abortion, but the second premise will require 
an argument. ${ }^{2}$ Abortion critics will not deny that a woman seeking an abortion has a fetus in her body and wants him out, but will deny that she may, at the cost of his life, put him out. When "nonconsensual use" is read this way, the second premise seems to amount to the claim that she may do so. I will come back to this in the next section and show that on this reading premise 2 is false. But before we get to that, I want to briefly address a related worry that is in the literature on "innocent threats."

For the self-defense argument to work, it must be permissible to kill an innocent person to prevent that person from using one's body in a serious way. And some recent work has argued that killing innocent threats of any kind is not permissible, although perhaps is excusable in some circumstances. ${ }^{3}$ If this is indeed the case, then self-defensive killing in the abortion context will not be justified. The reasons for thinking innocent threats-innocent people whose continued existence threatens another innocent person's life and limb—-may not be killed are complex and deserve to be discussed on their own terms, which I will not attempt to do here. Suffice it to say that if those arguments are sound, then the self-defense argument is obviously unsound. If you cannot kill an innocent person whose continued existence threatens your life, then presumably you cannot kill an innocent person who poses a lesser threat. The abortion debate would then just be a question about the fetus's moral status. That said, everything that follows here should be understood as conditional on the permissibility of killing at least some innocent persons in cases where they pose a threat to life and limb.

The philosophers who argue against the permissibility of killing innocent threats do so in the face of intuitively compelling cases where it seems like innocent threats may permissibly be killed. Thomson's expanding baby case is used in just this way, to sway the reader to think that it would be permissible to kill an innocent person whose continued existence is a threat to one's life. ${ }^{4}$ Roderick Long, a partisan of the self-defense argument, constructs a case to convince the reader that a threat to one's bodily autonomy can also justify the killing of an innocent person. Speaking of the innocence of the fetus as a reason to doubt that unwanted pregnancy justifies a lethal response, he says:

2 More accurately, we should say that "the fetus is in intimate bodily contact with her and she wants it to stop." As we will see, to be in this relation with another person does not require them (or part of them) to literally be in your body.

3 The most well-known defense of this sort of view is offered by Jeff McMahan. See his "Self-Defense and the Problem of the Innocent Attacker," The Ethics of Killing, "Self-Defense and Culpability," and Killing in War. Also see Doggett, "Recent Work on the Ethics of Self-Defense," for a review of the recent literature on self-defense.

4 Thomson, "A Defense of Abortion," 52. 
Considerations of the threat's innocence or guilt may legitimately affect judgments of the moral proportionality of the response. But when the threat is as personal and intrusive as an unwanted pregnancy, it is difficult to see how the innocence of the fetus could make enough of a difference to justify forcing the mother to quietly endure nine months of what is tantamount to rape. Analogously, even if someone has been involuntarily hypnotized into becoming a literal rapist, his victim still has the right to kill him in self-defense. ${ }^{5}$

According to Long, it is the serious nature of the threat- the intimate bodily contact the continued existence of the fetus imposes on the mother-that generates the permission to kill. And Long's hypnotized rapist seems as compelling a case as any for the claim that a serious threat to one's bodily autonomy can justify a lethal response against an innocent person.

\section{THE COUNTEREXAMPLE}

I want to adapt the case that Long has given us in the above quote. So, suppose that we have a person, $A$, who has control of a device-the hypnotizer-by means of which he can control the minds and bodies of other people, thereby robbing them of their agency and making them do what he wishes. $A$ then uses his device to make some innocent person, $B$, sexually assault another innocent person, $C$. To avoid any prurient details, call the act that $A$ makes $B$ do to $C \phi$ and stipulate that $\phi$ takes place over some period of time, that it involves a part of B's body being in C's body, and that this contact is both serious and sexual. So, for short, we have

Hypnotized Rapist 1 (HR1): A makes B $\phi$ C.

Long claims that $C$ would be within his rights to kill $B$, given that that was the only way for $C$ to avoid the $\phi$-ing. Notice that, in this case, if there is a rapist here, it is $A$. $B$ is not raping anyone; he is not doing anything. $A$ is using him as an instrument to torment $C$. But, by stipulation, $C$ cannot stop the event from happening without killing $B$, and regrettable as that might be, Long thinks it justified, given the nature of what $C$ will have to endure if $B$ is not killed. And if this is so, then we have a case where one is justified in killing an innocent person to avoid a violation of one's bodily autonomy, which is precisely what the self-defense argument maintains the mother may do to her unwanted fetus.

But even if this is so, the immediate rejoinder will be that while it is permissi- 
ble for a woman to kill an innocent man who has been hypnotized to "rape" her, as in Long's case, it would not follow that she is entitled to kill a man if she did the hypnotizing. That is, HR1 is unlike the typical unwanted pregnancy in that, in the latter, the woman bears responsibility for the use relation that obtains between her and her fetus. And this suggests a different case.

Keep $\phi$ the same, and now imagine we have only two people involved: $A$ and $B$. $B$ is an innocent person, and $A$ again uses the hypnotizer to control $B$ such that $B$ is now $\phi$-ing $A$. Call this

Hypnotized Rapist 2 (HR2): A makes B $\phi A$.

$A$, with the aid of the hypnotizer, causes $B$ to $\phi A$ in such a way that during that period of time, the only way for the $\phi$-ing to stop is for $A$, or someone else, to kill $B$. And during that time, $A$ decides that he does not want the $\phi$-ing to continue. So we have a case where $B$ is "using" $A$ 's body in a serious way and $A$ wants it to stop, but $A$ is not entitled to kill $B$ to stop it. Thus, premise 2 of the self-defense argument is false. It is not the case that $A$ is justified in using lethal force against $B$, even though the use relation obtains between them: $B$ is in $A$ 's body in a serious way, and $A$ wants him out.

Long defends the contention that even in such a case a person would be justified in lethal self-defense.

A woman never has an obligation-or at any rate, never has an enforceable obligation - to let herself be raped. That's moral bedrock if anything is. The notion of an enforceable obligation to let one's body be used by a rapist is a moral obscenity; and the same holds for the notion of an enforceable obligation to let one's body be used as an incubator by a fetus, even if the mother is responsible for the fetus' presence there in the first place. ${ }^{6}$

We should agree that there can be no obligation of any kind to let oneself be raped. But in HR2, $A$ is the rapist. To think that when $A$ changes his mind he has thereby withdrawn his consent to what $B$ is doing to him is absurd. $A$ cannot withdraw his consent to what he is doing, or has done, to himself. $B$ is not involved in the right way for there to be a consent issue in HR2. ${ }^{7}$ And so, premise 2

6 Long, "Abortion, Abandonment, and Positive Rights," 189. An "enforceable obligation" on Long's view is a moral obligation that any just society would enforce by law.

7 To avoid any misunderstanding, I am not saying that it does not make sense to talk about a person who has temporarily lost his agency and what he would or would not consent to. $B$ does not consent to what $A$ is doing to him, for example. But when one does something to oneself, the effects of which are not mediated by the agency of anyone else, then I think the idea of withdrawing one's consent from those effects makes no sense. A may regret what he 
of the self-defense argument is false. It is not the case that any serious, nonconsensual use of one's body by another justifies lethal self-defense.

Why is $A$ not entitled to use self-defensive force against $B$ ? The most obvious reason is that $A$ is responsible for bringing all this about; he has orchestrated this use of his body by $B$, and he is not licensed to put people into situations where they are a threat to him and then kill them in self-defense. To think otherwise would be to give a license to kill to anyone with the power to put other people in situations where they pose a serious threat.

Another possible explanation is that given $A$ 's role in bringing this state of affairs about, $A$ is not being violated by $B$ 's use of his body. While it is true in HR2 that $B$ is in his body in an intimate way and $A$ wants him out, $A$ is not suffering the sort of violation that $C$ suffered, or was going to suffer, in HR1. $A$ is not being raped. As I said before, for $A$ to claim that when he decides he no longer wants the $\phi$-ing to continue he thereby withdraws his consent to $B$ 's $\phi$-ing him is an absurd misrepresentation of what is going on between him and $B$. He cannot withdraw his consent to what $B$ is doing to him because $B$ is not doing anything to him. While there is sexual activity going on and $B$ is involved in it, $B$ is not involved in the right way for this to constitute a violation of $A$ 's bodily autonomy by $B$. And one might think that only such a violation would justify lethal self-defense against an innocent person. (Notice that this is consistent with thinking that it is morally permissible for $C$ to kill $B$ in HR1. In that case, $B$ is an innocent person who is being used as an instrument by $A$ to violate $C$. $A$ is doing the violating, not $B$, but we could say that one may defend oneself from any such violation, even if that defense involves killing an innocent person. $)^{8}$

Whatever the explanation for why it is not permissible for $A$ to kill $B$ in HR2, the question remains whether premise 2 can be revised to avoid the counterexample and still be general enough to yield the argument's conclusion, or something close to it. I am skeptical.

One could try to draw a distinction between the bodily relation between $A$ and $B$ and the bodily relation between the mother and fetus, and claim that the latter is even more invasive than the former. One could say that while $B$ is certainly in A's body in a very intimate way, $B$ is not enmeshed in $A$ 's body the way

has done to himself, wish things were different, curse the gods, or whatever, but he cannot withdraw his consent from anyone in HR2.

8 I do not mean to deny that there might be cases where it would be permissible for a person to kill an innocent person who is not violating, or going to violate, another person's bodily autonomy in the sense involved here. I just want to note that this might be an explanation put forth to explain why $A$ may not kill $B$ in HR2. There is still work to do figuring out just which situations justify lethal self-defense against innocent persons and which not, and how violations of bodily autonomy, or lack thereof, figure in. 
the fetus is with his mother, and it is this use relation that always justifies self-defensive killing, while other use relations need not. ${ }^{9}$ But trying to tighten up the relation in this way is going to beg the question. The self-defense argument is trying to prove that the bodily relationship between mother and fetus always justifies lethal self-defense, and trying to specify a bodily relation that is intertwined in just the way the fetus is with his mother is going to pull the conclusion into the premises.

We could restrict the self-defense justification in premise 2 to only those serious, nonconsensual uses of one's body that one is not responsible for having brought about. That is, we might say that if you are a mere bystander with regard to a serious, nonconsensual use of your body, then you are morally permitted to use lethal force to stop or prevent that use, but if you are responsible for the use, you are not so permitted. This would certainly avoid the counterexample. And something like this revised premise may well be true, but this will significantly restrict the scope of the argument's conclusion. The self-defense argument is an argument for (previable) abortion on demand, and to keep the generality of its conclusion, such a revision of premise 2 will require that no woman bear responsibility for her pregnancy. Since this is not true in most cases of unwanted pregnancy, the self-defense argument would then apply only to those cases in which the woman is not responsible, and so will at best show that abortion is permissible in cases where we (or most of us, anyway) already agree abortion is morally permissible.

One might deny that the woman who has consensual sex that results in pregnancy is thereby responsible for the fetus that results (or might claim that she bears some diminished responsibility different in kind from the responsibility $A$ has for putting $B$ in the situation involved in HR2). And I will concede that if it is demonstrated that a woman in a typical pregnancy is a mere bystander with regard to the fetus's use of her body, then the counterexample will have been avoided. There is a great deal of literature dealing with responsibility for pregnancy and its implications (if any) for abortion. ${ }^{10}$ If the defenders of the

9 In The Ethics of Killing, McMahan, although not a defender of the self-defense argument, expresses this thought in the following way:

In some respects, pregnancy is even more invasive than rape. Another individual's entire body becomes lodged within the pregnant woman's body and draws sustenance from it. And, unlike rape, the invasive process continues for nine months unless it is forcibly arrested. If, therefore, the threat to bodily integrity from rape is sufficiently serious to warrant a lethal defensive response, it seems that the more deeply invasive and enduring threat from pregnancy should be as well. (399)

10 For those interested in the responsibility debate concerning abortion, see chapter 4 of David Boonin's A Defense of Abortion and the citations therein. One thing I will note about 
self-defense argument want to take this tack, then they will have to engage with that literature and make their case. But to make the issue one of responsibility is, I think, to abandon the self-defense argument rather than defend it. The promise of the self-defense argument was that it would elide such complications by appeal to the stringent nature of a woman's right to bodily autonomy. To admit that the issue of responsibility is crucial to the defense of abortion, then, is an admission that the right to bodily autonomy is not up to the task. ${ }^{11}$

That said, one could revise premise 2 by appealing to the obvious difference in the intentions of the two relevant parties in the cases. In HR2, as described, it is clear that $A$ intentionally puts $B$ in a serious bodily relationship with himself, whereas in the typical unwanted pregnancy, the mother does not intentionally put a fetus in an intimate relationship with herself but merely foresees that such a relationship might occur. So, we could restrict premise 2 to refer only to those serious bodily relationships one did not intentionally bring about but merely foresaw might come about as a result of one's actions. Since we generally think

responsibility and abortion is that the literature takes it that what is at issue is what your obligations are to those needy persons you create through your voluntary actions. That is, whether responsibility for creating them, as is the case in the typical pregnancy, places an obligation on the creator to provide aid to the created. Abortion critics say yes; abortion defenders, like Boonin, say no. What will make this more difficult for the partisans of the self-defense argument is that given their commitments, not only has the pregnant woman created a needy person but she has also put that needy person in a serious, nonconsensual bodily relationship akin to serious sexual activity. This, I argue in what follows, makes it much harder to avoid the conclusion that the mother's responsibility, however parsed, gives the fetus a strong claim against her killing him.

11 Some think that Thomson's people seed case is relevant here in that they believe she has more or less successfully argued by analogy that even if the mother is responsible for the fetus being in her body, it is still morally permissible for her to get an abortion. See Thomson, "A Defense of Abortion," 58-59. This is the wrong way to understand the people seed case. Thomson is considering an argument that abortion is morally impermissible because it violates a "special right" the fetus has to use his mother's body, and the fetus is supposed to have this right because the mother engaged in consensual sex knowing that it might result in pregnancy. Thomson asks why the fetus has this special right and anticipates the response that this is so because the mother could have done, or refrained from doing, something such that the fetus would not now be using her body. Thomson's examples in this part of her paper, including the people seeds, are an attack on the claim that this fact is sufficient to establish that the fetus has this special right to use his mother's body. That is, the people seed case is a counterexample, not an analogy. Thomson does not claim (for good reason) that it would be permissible to kill the people described in these cases; she only claims that they do not have a special right to be using the things they are using simply because one could have done something that would have kept them from using those things. The cases in this section of Thomson's paper, then, do not show that abortion is permissible in any case. For an illuminating discussion on how Thomson's various examples are used-and, just as importantly, not used-in her paper, see Watkins, "Re-reading Thomson." 
it is worse for a person to intend to put someone in a bad way than it is for a person to do something they (merely) foresee might put someone in a bad way, this seems a plausible attempt to revise the premise to deal with the counterexample and still get to the general conclusion the self-defense argument attempts to establish.

While I grant the general moral distinction between intending and foreseeing being invoked here, that distinction is consistent with there being some things one can be held liable for, even if one did not intend for them to come about. And creating an intimate bodily relationship of the sort that motivates the self-defense argument is just such a case. No one is going to pardon $A$ for killing $B$ if $A$ knowingly did something that would bring $B$ into the bodily relationship we have in HR2, even if $A$ did not intend to bring about that relationship but merely foresaw that there was a reasonable chance it might occur. I realize that "might" and "reasonable chance" are controversial claims in the abortion context, but in HR2 they are not controversial at all. If doing something that has, say, a one in twenty chance of bringing about an $\phi$-ing relationship with an innocent person is something you voluntarily do, then we would hold you liable for it, even if you did not strictly intend for the $\phi$-ing to come about. And so, the liability the mother has for her fetus will be the same liability that $A$ has for $B$ in HR2, given that she had consensual sex that she knew might result in the relationship between her and her fetus, whether she intended to bring it about or not.

There is obviously much more to be said about possible individual cases of unwanted pregnancy, responsibility, and intention: there are "cases and cases," as Thomson reminds us. I only appeal here to HR2 and what would be permissible for $A$ to do to $B$, even if it were the case that $A$ did not intend to bring about the intimate bodily relationship but merely foresaw there was a reasonable chance it might occur. That one's voluntary actions might impose that relationship on another person raises the stakes considerably. And since the defender of the self-defense argument views any pregnancy as morally akin to serious sexual activity, it is fair to make a comparison between a typical unwanted pregnancy, which I grant is not intended, and the relationship that $A$ brings about in HR2. As we will see, understanding the pregnancy relation in this way, in addition to thwarting the proposed revision of premise 2 by reference to the distinction between intending and foreseeing, will lead us to some more radical conclusions concerning abortion.

3. AN ANALOGY ARGUMENT FROM HR2

Now, HR2 is just a counterexample. If what I have argued so far is correct, it mere- 
ly shows us that a premise in the self-defense argument is false. An abortion critic could attempt to make an analogy argument from HR2 to the moral impermissibility of the typical abortion, but this looks like it will be tough going; in fact, the differences between the cases look so stark that it seems bizarre to seriously entertain the comparison. First, in HR2, $A$ harms $B$ by putting $B$ in that intimate bodily relationship with himself, but it is far from clear that a woman harms a fetus by conceiving him. And the harm that $A$ visits upon $B$ is surely relevant to our judgments about what it is permissible for $A$ to do to $B$ in HR2. Second, one might reasonably doubt that there really is a symmetry in the use relation between the cases. After all, the woman is not using the fetus for anything; it is the fetus that is in the woman's body, and if anyone is using anyone else in the pregnancy relationship, it is the fetus using his mother. This, at least on the face of it, seems different from what is going on in HR2. Third, $B$ in HR2 is a normal human being who will be aware of the harm done to him and will, if he lives, suffer the consequences long after the event itself, whereas a fetus will not be aware of anything. One could argue that this is a morally relevant difference between the cases as well. So, it looks like an analogy between HR2 and the typical pregnancy will not hold together. ${ }^{12}$

But there is still a worry here, and it is generated by the use relation involved in the self-defense argument. If the use relation between mother and fetus is morally akin to intimate, sexual activity, then it is going to matter who puts whom in that relation. In HR2, as I noted above, with $B$ being placed in the situation without his consent, it is $B$ that is suffering a violation of his bodily autonomy. He is the victim. So, any person who puts another person in that use relation without that other person's consent will be violating that person's bodily autonomy. $B$ could, for example, invoke self-defense as a justification for killing $A$ to stop the $\phi$-ing, if only he could and killing $A$ was the only way to stop it. And a third party would be justified in doing so on B's behalf. Given this, why is it not the case that a mother violates the fetus's bodily autonomy by putting him in an intimate relationship with her; why is she not guilty of a violation of a kind that $A$ is guilty of? And if she is, why do the same considerations not weigh against the mother's killing her fetus by abortion? After all, she put him in that intimate relationship without his consent and now plans to kill him to end it.

I am going to defend the analogy argument from HR2 to the moral impermissibility of abortion, not because I think it shows that abortion is morally im-

12 There is the difference in intentions between the parties in the cases that one might point to as a morally relevant difference. But if what I said above concerning the distinction between intending and foreseeing and its (ir)relevance to our judgments concerning HR2 is correct, then this will be a morally irrelevant difference between the cases. 
permissible, but because I think it shows us that the conclusion the self-defense argument is supposed to establish—that previable abortion is morally permissible-is undermined by its premises. Thinking of the relationship between mother and fetus as partisans of the self-defense argument do, coupled with the facts concerning the typical unwanted pregnancy, leads to the opposite conclusion. I will work my way through the differences I mentioned above, and I will argue that the differences between the cases are not morally relevant as long as we are committed to understanding the pregnancy relationship as being comparable to serious sexual contact between two normal human beings. This commitment makes the seemingly bizarre comparison between HR2 and a typical pregnancy apt. This commitment is my target.

The first objection to the analogy argument concerns the harm that $A$ visits upon $B$ in HR2 that does not appear to be present in the typical unwanted pregnancy. In HR2, it is clear that $A$ harms $B$ by putting him in the bodily relation. $A$ has kidnapped and raped an innocent person. And $A$ is now, on top of all that, going to kill him. No one will shed tears over A's predicament in HR2. But a mother, even if she deliberately conceives a fetus, has not thereby harmed the fetus. And the prior harm that $A$ has done $B$ is surely relevant to our judgment concerning the impermissibility of his killing $B$.

This objection depends on the fact that in HR2, $B$ exists prior to the act that puts him in the relationship with $A$. When $A$ does what he does, he violates $B$ 's liberty rights and $B$ 's right to bodily autonomy. And this is very different from what the mother does when she becomes pregnant by consensual sex. The fetus does not exist prior to the act that causes him to be in the relationship and cannot exist unless he remains in it. So, the objection goes, the fetus is not harmed by being put in that relationship, nor does it harm him to remain in the relationship after it is brought about.

Now, while it is true that the fetus's existence depends on his being put into that relationship, if we are to take seriously that that relationship is morally akin to serious sexual activity, we cannot maintain that being put in that relationship does not harm the fetus or, if this is different, that it does not violate his bodily autonomy. It is a commonplace that conceiving a fetus does not harm the fetus since one cannot be made worse off by being brought into existence (unless one's life is not worth living), but this will only be true as long as we do not think the relation thereby established is a violation of his bodily autonomy. In the pregnancy case, the act that results in conception is the act that creates the bodily relationship. If being put in that relationship without one's consent is a serious violation of one's bodily autonomy, the fetus will suffer from the violation, even if the same act brought him into existence. If instead of $A$ kidnapping $B, A$ 
simply created him in his garage and then brought him into the bodily contact involved in HR2 - or, better yet, it was the case that $A$ could only create $B$ by also making it the case that they were in the same sort of bodily contact described in HR2-it would not be permissible, given that $B$ is an innocent person, for $A$ to perform the act that created $B$, nor would it be permissible, given that the act was already performed, for $A$ to kill $B$ in order to end the bodily contact that $A$ brought about. ${ }^{13}$ The very act that brings on conception would be a morally impermissible act, given that the use relation that results is akin to serious sexual activity. Since one cannot obtain a fetus's consent before the fact, conceiving a fetus will constitute a violation of his bodily autonomy.

Furthermore, it will not matter that the fetus cannot continue to exist without being in that relationship. It is true that the mother can end the relationship without the loss of her life and the fetus cannot end the relationship without losing his. But in HR2, $B$ cannot survive without remaining in a condition of intimate bodily contact with $A$ once the contact is initiated. $B$ is just as dependent for his survival on a continued bodily relationship with $A$ as the fetus is with his mother, and still suffers a violation of his bodily autonomy, regardless of his need to maintain that relationship to survive. If this is the price of existence, we might be willing to suffer it, but it is not something we could visit upon an innocent person absent his consent.

So, the fact that being brought into existence, when considered by itself, does not harm the person brought into existence is not a reason to think there is anything wrong with the analogy argument. And crucially, it is the nature of the relation between mother and fetus as the partisan of the self-defense argument understands it that does the work in holding the analogy together.

The second objection I mentioned above concerns the location and activity of the fetus in a typical pregnancy. He is in the woman's body, using her resources, changing her hormones, and so on. She is not using him for anything. We cannot therefore believe that there is a symmetry in the use relation between mother and fetus and the use relation between $A$ and $B$ in HR2, where $A$ is subjecting $B$ to his nefarious purposes.

However, if the use relation is what partisans of the self-defense argument say it is, it does not matter who is in whose body. For example, a woman could rape a man without putting anything in his body, and the man would be entitled to self-defensive action if that were the only way to stop the woman from carrying out the rape. And this is exactly the sort of relationship we have between $A$ and $B$ in HR2, where (part of) B's body is in A's body. Even though A's body is in inti-

13 The garage case is one Michael Davis came up with in his "Foetuses, Famous Violinists, and the Right to Continued Aid," 277. 
mate contact with B's body, there is no part of A's body in B's body. But it is still the case that $A$ may not kill $B$ to end the intimate contact that $A$ brought about. Given that there is intimate contact between mother and fetus and this intimate contact is as morally fraught as serious sexual activity, it does not matter who is in whose body; all that matters is who put whom in the relationship. And as for the fact that the fetus is "using" his mother's body to survive, we have already seen that $B$ 's survival in HR2 requires his continued bodily contact with $A$. It is hard to see that a difference in the details concerning why this bodily contact is needed for the survival of the fetus and why it is necessary for the continued survival of $B$ is a difference that would compromise the analogy.

The last worry about making the analogy argument is that as HR2 is described, $B$ is a normal, innocent person that $A$ kidnaps and rapes. Surely $B$ will suffer the violation visited upon him in a way the fetus will not in an unwanted pregnancy. The fetus is not aware of what is going on, and will never be aware of it if aborted.

But whether the harm, or violation, is perceived does not matter. We could easily imagine that $B$ is rendered unconscious by the process of coming to $\phi A$, that he remains so during the $\phi$-ing, and further that he is never made aware of what happened. This makes no difference to what $A$ is entitled to do to him, and so it makes no difference that the fetus is not conscious of his mother's "use" of his body. If one party, either intentionally or negligently, puts the other party in that use relation without the other party's consent, they will have thereby violated the bodily autonomy of the other party. I do not see how this is to be avoided. It does not matter who is in whose body or whether the victim is aware of the violation as long as the violation occurs.

Now, analogy arguments being what they are, I cannot prove there are no other differences that make a moral difference. I can only say that I do not see any that would. But the point of the analogy argument is to put pressure on the idea that the mother-fetus relationship is subject to the same norms that govern intimate bodily relationships among normal human beings. Imposing the sort of relationship under consideration here on another without their consent is a crime. Imposing it on the fetus, given that he is a person at conception, will not differ on this score.

\section{CONCLUSION}

But again, this all depends on the relation between mother and fetus being what the partisan of the self-defense argument thinks it is. That it leads to a position critical of abortion is a reason for the abortion defender to let it go with both hands. That it leads to the conclusion that the typical pregnancy is a violation 
of a fetus's right to bodily autonomy - that each discrete, voluntary act of the propagation of our species is an act comparable to sexual assault-gives us all a good reason to think that this rape-analogy business was a bad idea and that the self-defense argument that relies on it is indefensible.

I will not pretend to know how the relationship between mother and fetus is to be understood, given that the fetus is a person. All I hope to have done here is to show that one way of understanding it cannot be correct. That relationship cannot be understood as a relationship subject to the norms that govern intimate bodily relationships between normal adult human beings. Thinking of the pregnancy relation in this way has implications that neither party to the abortion dispute can accept.

Auburn University hhhooo1@auburn.edu

\section{REFERENCES}

Boonin, David. A Defense of Abortion. Cambridge: Cambridge University Press, 2003.

Davis, Michael. "Foetuses, Famous Violinists, and the Right to Continued Aid." Philosophical Quarterly 33, no. 132 (July 1983): 259-78.

Doggett, Tyler. "Recent Work on the Ethics of Self-Defense." Philosophy Compass 6, no. 4 (April 2011): 220-33.

Little, Margaret Olivia. "Abortion, Intimacy, and the Duty to Gestate." Ethical Theory and Moral Practice 2, no. 3 (September 1999): 295-312.

Long, Roderick. "Abortion, Abandonment, and Positive Rights: The Limits of Compulsory Altruism." Social Philosophy and Policy 10, no. 1 (Winter 1993): 166-91.

McDonagh, Eileen L. Breaking the Abortion Deadlock: From Choice to Consent. New York: Oxford University Press, 1996.

McMahan, Jeff. The Ethics of Killing: Problems at the Margins of Life. New York: Oxford University Press, 2002.

- Killing in War. New York: Oxford University Press, 2009.

- "Self-Defense and Culpability." Law and Philosophy 24, no. 6 (November 2005): 751-74.

. "Self-Defense and the Problem of the Innocent Attacker." Ethics 104, no.

2 (January 1994): 252-90. 
Regan, Donald H. "Rewriting Roe v. Wade." Michigan Law Review 77 (1979): 1569-646.

Thomson, Judith Jarvis. "A Defense of Abortion." Philosophy and Public Affairs 1, no. 1 (Autumn 1971): 47-66.

Watkins, Michael. "Re-reading Thomson: Thomson's Unanswered Challenge." Journal of Libertarian Studies 20, no. 4 (Fall 2006): 41-59. 